\title{
A digital society for all? - Meanings, practices and policies for digital diversity
}

\author{
Irene Bernhard \\ University West \\ irene.bernhard@hv.se
}

\author{
Mariana Gustafsson \\ Linköping University \\ margu72@.liu.se
}

\author{
Karin Hedström \\ Örebro University \\ karin.hedstrom@oru.se
}

\author{
Johanna Sefyrin \\ Linköping University \\ johanna.sefyrin@liu.se
}

\author{
Elin Wihlborg \\ Linköping University \\ elin.wihlborg@liu.se
}

\begin{abstract}
The concept of digital divides has been on the agenda in research and policy making for at least the last 20 years. But it is still, a challenge to grasp this concept that is so elusive and transforming. Inclusion, access and equality are still key values for democratic governance and must be addressed in particular when forming and contributing to a digital government. This paper seeks to intervene in current debates on digital divides and digital inclusion by analyzing two cases of responses among street-level public administration in relation to e-government services in Sweden. The case studies are strategically chosen and conducted in national agencies and in local public libraries. Three lines of contributions are discussed, firstly the importance to care for equality secondly the need to see the non-users, and thirdly to discuss the potential of putting focus on digital diversity.
\end{abstract}

\section{Introduction}

Equal access to public services is fundamental in a universal democratic state. This means that public services must be equally accessible for everyone as well as being impartial to maintain a high quality of government [1]. However, as the Internet matures and the digitalization of public sector services advances, new forms of digital exclusion proliferate [2]. Considering the pervasive role of technology in today's society, digitalization inevitably changes how an equal society can be built and how equality is formed in new social settings.

The Swedish Government has the ambition, according to the National Digital Agenda [3], of using the full potential of digitalization to become the world leader in harnessing the opportunities of digital transformation. Public welfare services are accessed and used through digital platforms, and welfare services such as sickness benefits and parental leave are provided by the Social Insurance Agency [4]. The large national agencies and municipalities, the main providers of public services, are developing their digital services and including new forms of automation [5]. Such services require the user to have sufficient opportunities and trust to access and use this technology to get public services. New forms of inequalities follow in the tracks of digitalization and there are new demands to allocate staff at public agencies to support the users and their needs to get guidance and practical help in using digital governmental services.

Today there is a plurality of aspects that can exclude different groups from accessing public services through digital means. It is no longer enough to just look at the digital divide as access to Internet and personal computers in the households, as when the problem was first identified in the late 1990's [6]. As the Internet coverage has increased and opened for more groups to access and use services online, such diversity also opens for new dimensions of inequalities and new ways to be excluded. However, there is not one clear and specific way to support people in becoming digitally included citizens. For example, the young gamer spending almost all of her day on-line in interactive games can still be excluded when it comes to participating in democratic discussions or when to apply for unemployment benefits from the public agency. The middle aged man with a permanent job and income, on the other hand, can feel completely excluded when his bank asks him to use only on-line services or when he has to submit his income tax declaration on-line. These simple examples indicate that there is a need to address a plurality of inclusion and exclusion in the context of digital diversity.

To guide and structure the complexity around digital divides and inclusion we will use a model and categorization of approaches presented by Jaeger et. al. [7]. In their work they conceptualize digital divide, digital literacy and digital inclusion. They mean that digital divide focuses on the gaps and divides that can be identified in relation to use as well as non-use of digital technologies, and how it relates to socioeconomic status, education, geography, age, language, or other factors. Digital literacy, on the other hand, encompasses the skills and abilities necessary for access to technology and it also includes the levels of necessary competences and understanding required to successfully make use of the technology. In addition to these more descriptive concepts of different practices they consider, digital inclusion as the policy "... to close the digital divide and promote digital literacy" [7].

They relate their discussion to the roles of public libraries based on case studies in the US and concludes that the public library functions as a capable intermediary closing the digital divides, supporting digital literacy and digital inclusion [7]. We will here 
draw on this division by letting the three concepts guide a research overview of the debates on digital divides, digital literacy and digital inclusion. Subsequently, these will be applied on to practices by street-level bureaucrats at local public libraries and national agencies in Sweden. Our case studies at the public libraries are set in a welfare state model. This in stark contrast to Jaeger et. al. and Bertot et. al. [7, 8], as the Swedish public funded welfare services are much more advanced and extensive than the related ones in the US /Swenson, P.A., Capitalists against market/. The same reason made us include a case study conducted at the contact centers at two national agencies providing and organizing main aspects of the social services employment benefits and employment matching at the Swedish Public Employment Agency (AF) and the extensive social insurances at the Swedish Social Insurance Agency (FK), mainly including sickness benefits, pensions and parental leave.

\subsection{Aim of the paper}

This paper seeks to contribute to current debates on digital divides, digital literacy and digital inclusion by analyzing two cases on practices among street-level public administration in relation to digital public services in Sweden.

\subsection{Research design}

This paper reports two first stages on recently initiated research. The paper has grown out of interactive research where we together with different policy making organizations and networks as well as public agencies and local governments are striving to find ways to support initiatives to increase digital literacy and inclusion as a way to address inequalities. The research is still in the phase of networking for a broader understanding on how technical, social and organizational strategies are embedded into the processes and local practices [9]. The case of Sweden in terms of advanced use of digital public services can be compared with other similar cases such as the US or other western democracy, even though these are based on different welfare systems.

We have complimented the ongoing interactive work with a research overview presented in the first part of this paper. Our work so far builds on two qualitative field studies in public organizations - local public libraries and national agencies with a focus on the changing roles of the street level bureaucrats. The main research methods are document analysis, observations and primary interviews with in total 12 people at different positions. All interviews have been conducted in Sweden at the sites of the informants' work places and lasted approximately 45 minutes. Some interviews were made as group interviews. All transcripts are in Swedish and when translating quotes to English we have also made small adjustments to make the expressions meaningful. The analyses of the qualitative case studies were guided by the categorizations provided by Jaeger et al., [7]. However, since the coding of the statements often were complex and related in particular to a combined interpretation of digital divide (access) and digital literacy (competence) there are no summarized presentation of the interview results. Instead we highlight the need for more developed and contextualized analysis that we aim to elaborate on in further interactive research approaches [9].

\subsection{Outline of the paper}

This paper proceeds in four steps. In the subsequent section, we discuss the importance of these discussions for the research field of digital government or egovernment. In the third section, we will present a research overview focusing on digital divide, digital literacy and digital inclusion as a policy response, following Jaeger et. al. [7]. Thereafter in sections four and five we present two case studies on challenges regarding digital divides, digital literacy and digital inclusion, each of the case study is introduced by a general case setting and the methods of the field study is described. In the following, and sixth, section we elaborate on the concept of digital diversity as a response to the challenges in practical use of digital inclusion to bridge digital divides and to increase digital literacy, this also opens for a discussion on the contribution to the field of digital government and further research.

\section{Digital government and the challenges of inclusion - setting the discussion in relation to the e-government field}

This discussion on digital inclusions is set in relation to digital government, e-government. We argue that inequalities regarding access and competence to digital tools and services here play a more crucial function than in other areas of the society where digitalization takes place. E-government refers to the general use of digital media in governments and includes both human and technical components in a socio-technical framing. The focus on the interplay of technology, data and processes underscore the organizational aspects [10]. Yildiz [11] argues that e-government cannot be defined by technology, but that it is rather about a continuing organizational development. The institutional arrangement of governments is framing e-government 
and its impacts of policy implementation [12]. A central part of e-government is the digitalization of services aimed at citizens and business, but are pointless if they are not used by their intended users [13, 14]. This requires that the design of these services is based on detailed knowledge of their intended and probably heterogeneous users; of their needs, their knowledge, their socioeconomic context and other prerequisites for using the services $[15,16]$. If this is not done, some of the intended users will rather be non-users, and hence divides will appear.

\section{The many digital challenges - divides, literacy and inclusion}

In this section we return to the conceptualization of Jaeger et. al. [7] and present a research overview by discussing research on digital divide, digital literacy and digital inclusion as the policy responses. This research overview is based on a strategic search in Scopus and the e-Gov Reference Library (EGRL) which is a wellused database encompassing e-government research, on a palette of concepts relating to digital divides, digital inclusion and digital literacy. In addition, we have grounded the overview in some more general literature to structure the presentation.

\subsection{Digital divide}

Digital divide as a concept has been used both in academic analyses and policy making and there is a basic ambition that when mapping out digital divides they can and need to be closed. The concept was introduced to the broader audience and given political attention by Pippa Norris in the late 1990's [6]. Since then the concept has been discussed and challenged both in research and policy practices. Thus, the concept today has several meanings and implications, but the focus is on how access to unequal access to digital technologies give rise to divides $[17,18]$. Other research $[6,19]$ has shown that social divides in non-digital contexts are mirrored but also partly re-framed in digital contexts. Policy makers seem to assume that once citizens have access to the required technologies, they will also use public e-services [20]. However, studies show that everyone does not want to be active digitally. A recent statistical study shows that about half a million swedes - most of which are over the age of 65 - do not use internet at all, because they lack interest and do not see the value of it [21]. These and other differences have in research shown to be in line with other socio-economic parameters as income and education [22]. Today as the public sector and services globally are moving towards digitalization there are increasing consequences of the digital divides and more challenging tasks for and demands on public service providers [23]. It has also been shown that the rapid development of Internet and other digital technologies continue to outpace the capabilities of many users, and new access challenges and inequalities grow when digitalization increases [7].

\subsection{Digital literacy}

According to research on digital literacy, access to technology is not the only issue that is required for citizens to use public e-services, but necessary skills are also a prerequisite. In this respect, there are groups of people (e.g. the elderly) who tend to be excluded from benefiting from digital technologies for a variety of reasons [16-18]. Other researchers underscore that there is a need to also have competence about the society, and the social norms $[2,13,16]$. A recent study on immigrants integration and social inclusion in Mexico [16] concludes that "the social context goes well beyond the digital divide and includes additional important factors like extreme poverty and legal vulnerability". We draw similar conclusions when transforming a library bus to a digital media bus and extending the routes to socio-economic weak neighborhoods [24].

The public libraries have for a long time had the role of a cultural mediator and work for increased public education. The libraries thus provide several digitalized resources and information sources and often get assigned to promote the users' competences and to improve the knowledge needed to be a part of the digital society [22]. There are also related practices provided by public agencies like municipal offices and community centers, and in Sweden these played an important role already in the late 1990's [25].

\subsection{Digital inclusion}

In the early work on digital divides [6] there were also discussions of how to extend access to digital technologies $[16,24,26]$. Digital inclusion refers to the need to work with strategies and policies to close the digital divide, and increase digital literacy in order to achieve digitally included citizens.

Commonly users (citizens) are seen as potential adopters and as the last link of chain of actors in the implementation process. There is a poor understanding for the determinants of demand on digital services among citizens since public digital services often are designed from an organizational perspective rather than from the perspective of the users [27, 28]. Often, the result of such approaches leads to low adoption and use, and even more in the most marginalized groups of citizens. Helbig et al [13] argue for the need to consider how public managers' assumptions about e-government and digital divide issues influence the design. Such a 
poor and often normalized understanding and modelling of who the users are is embedding several problems in processes of "demand driven development" [29] Thus, Gidlund and Sefyrin [29] argue that design of public eservices has to be guided by an open-minded approach to the concept of user. Thus, there is a need to try to look beyond the normalized user categories to get guidance for how to deal with digital inclusion. Such an approach is in line with more sociological and even anthropological approaches, making research open and all-inclusive $[15,30]$.

\subsection{Concluding remarks on digital challenges in the research}

The research on digital inequalities is so far mainly based on case studies. There is still a lack of a coherent conceptualization in the research that can guide the state of art in this emerging field. The structure that we have chosen to follow here [7] 'The Intersection of Public Policy and Public Access:/ is clear and indicate a lack of research on policies towards inclusion. Robinson et. al. [2] point to the need for more in-depth research on the relationships between digital inequalities and other forms of inequality, since the ever more seamless integration of digital technologies into everyday practices can create disadvantages. In the two following sections we will still use the same concepts to structure impressions from our two field studies.

\section{The librarians and other street level bureaucrats at public libraries addressing digital challenges}

In line with the cases presented by Jaeger et. al. [7] above we are conducting a case study on how libraries work on digital inclusion in different ways. Thus, we will now present and discuss an on-going research project in local public libraries.

\subsection{Our fieldwork methods at the public library}

This case study focused on the daily interactions among citizens and librarians at local public libraries in the region of Östergötland and in particular the two municipalities of Motala and Norrköping that has a generally weaker social economic status than the rest of Sweden as old industrial urban regions still struggling with re-structuring. The library in Motala has worked indeed innovative in collaboration with the DigiDel network to enhance digital inclusion and bridge digital divides. They have also recently got additional national funding to spread the models and strategies to other libraries. The field work took off as some open field observations adopting an inductive approach [31, 32], by starting with observations at a local library mainly in relation to activities arranged by the network DigiDel, promoting increased digital participation and digital literacy. We have so far conducted five interviews with librarians and the library management, analyzed documents such as digital strategies, action plans, DigiDel reports and more general reports on digitalization related work carried by libraries. The initial results of the study have been reported and discussed in Gustafsson, et.al. [33].

\subsection{Digital inclusion through and at the libraries}

In Sweden the local public libraries played a crucial role in the early development of the welfare state by supporting literacy, the people movements and democratization up until today [34]. As in many countries, the public libraries play a key function in making the Internet more available and open for all the inhabitants, by free use of connected online-computers [35]. In the context of advancing digitalization, the library's role has expanded to include digital literacy by ensuring access to veridic information, support learning and facilitate access to public services through free digital infrastructure.

The mission and the mandate of the public libraries in Swedish municipalities are based in Library Act [36] that stipulates (since 2014) the democratic right to be digitally included [37]:

$\S 2$ The libraries in the public library system shall promote the development of a democratic society by contributing to the transfer of knowledge and the free formation of opinions. The libraries (...) shall promote (...) an interest in learning, information, education, and research (...). Library activities shall be available to everyone.

$\S 7$ (...) Public libraries shall act to increase knowledge about how information technology can be used for the attainment of knowledge, learning, and participation in cultural life.

In addition to the national legislation, the local government in the regions and each municipality have mandates to shape their public libraries and engage in special arrangements. Thus, there are also regional and local policy documents steering the work. In our case the Regional Library Plan sets specific focus on digital inclusion, targeting integration.

In the region of Östergötland the Regional Library Plan emphasizes the digital inclusion as a question about democracy [38]. This document is adopted by the Regional Council and says: 
Efforts need to be made to increase the digital skills and involvement of the region's inhabitants. It is an important democracy issue. / ... / Special efforts will be needed to strengthen the libraries work to increase digital participation.

To ensure that all libraries in the region of Östergötland can and will work with questions about our digital society, digital inclusion and media and information knowledge, the Regional library has allocated resources for one person focusing on these issues in particular with an aim to support each local library. This indicates that they take the policy ambitions one step further to ensure implementation and changes in practices.

\subsection{Discussions on digital divides at the libraries}

The librarians and staff at the local libraries had a clear knowledge on the diverse access to digital tools and services. They received many questions from the library users regarding how to access and use their own devices. Despite that the users had access to digital tools, they had difficulties to grasp and manage the technology enabling their devises. The librarians witnessed that the questions at the helpdesk have changed through time. The users bring their own devices and are asking for help with programs and services connected to the library's own and other digital services. One of the staff at the library said:

The questions are different, many bring with them their own tablets or smartphones and want to get help with various features, download apps, get started with different programs, transfer pictures, book tickets, manage files, using the Internet bank, lend e-books, download talking books, etc. They come to both our Drop in and the booked tutorials. It is very appreciated.

Accessibility to information and knowledge acquires complexity as it is mediated by more technologies. Libraries need to keep up with knowledge about the new digital media landscapes. It was clear at the library that the users, having access to their own devices, could experience a divide and inequalities that made them asking for help at the library.

In addition to the questions related to the use of technologies and library's own services, the interviewees experience and increasing number of questions linked to knowledge of government functioning and public services in Sweden. In practice, these are the users of services of the Swedish Public Employment Agency (AF), the Swedish Social Insurance Agency (FK), and the municipality. This raised internal debates among the library staff on responsibility, resources and the need for cooperation with the respective authorities in terms of delivery of information and services to these groups of users. Such a function was included in Digidel Center.

It's frustrating... that they send them here because they can't help them at their place. The other authorities must engage in this and help with this. It's their responsibility too. We have started with the municipal administration - 'the Bridge'/Bryggan that works with refugees. They have one of their people who come to Digidel Center and guides the users on municipal services in several languages.

At the same time the libraries, through the Regional library cooperation, already work with government and public service related information through their introductory courses for refugees. The introductory information seems however not enough as many of them end up eventually at the municipal libraries with their specific questions on accessing and navigating specific public services. Understanding what a specific service involves in terms of rights and obligations for the user is therefore a prerequisite for the user to be able to access and use the service also online.

\subsection{Discussions on digital literacy at the libraries}

One central challenge for the library is to keep up the pace of information technology development and its enabling affordances to reach out to the wider and more diverse groups of users and their needs. They have an awareness of the visitors, diverse needs and their different levels of digital literacy, as said by one of the librarians:

The modern public library must respond to completely different needs, in order to feel relevant and important to the people. The great challenge for today's library is to open the doors to the digital world, and help people navigate the digital information jungle. The library is a digital knowledge disseminator, which helps bridge the knowledge gap in our society when it comes to using digital media. It is about democracy and education in our times.

These complexities regarding digital literacy indicate a need for high competence and flexibility by the staff at the libraries. Visitors are asking for support in almost any issue on a drop-in basis, daily that the staff cannot prepare for. For the staff it also becomes a question of time and prioritizations, since some issues take time to solve, even if they have ambitions to provide help-for- 
self-help (and not just solving the problem instead of the user), as was explained by one of the librarians:

As for example yesterday afternoon, when I worked at the information desk, we had a lot to do. We had many issues coming and some of these took much longer time. We had to push ahead. These issues require know how, especially the teaching part. And it is difficult to manage in terms of time. Most often they come with a problem that they need to solve on the spot. It is difficult to tell them to come later.

This shows that digital literacy is something they try to address, but it needs a lot of resources such as time and competences to improve digital literacy in practice. It is also obvious that there is indeed a diversity of digital literacy needs the users come with searching help from the libraries. The staff at the library cannot have the competences nor the preparedness to meet all these demands.

\subsection{Concluding remarks on digital diversity at the public libraries}

To conclude on the initial results of the library study, their work with digital literacy in pursuing digital inclusion has to be understood in the context of the fundamental changes in how libraries work to follow digital developments. Keeping up with the fast pace of the digital development poses challenges for the libraries in terms of updated knowledge, technology devices, money and time when they have to meet the users' diverse needs for support. More media channels and more advanced digital support software and devices provide enabling opportunities for more and new groups that were previously excluded, to access services and information online in their contact with authorities. These opportunities involve more access in general, but new literacy needs arise, as witnessed by the librarians in our study. If these needs are not addressed effectively, new forms of exclusions will emerge.

\section{The digital services at national welfare agencies}

Common issues about digital diversity that were brought to the library related to the use of digital services at public agencies. The government demands the national agencies to increase efficiency by digitalization and closing down personal support and services. The front-line officers here are assigned to promote use of digital tools, mainly since it can contribute to internal efficiency.

\subsection{Our fieldwork at public agencies}

Two of the main public agencies in the Swedish welfare state are the Swedish Public Employment Agency (AF) and the Swedish Social Insurance Agency (FK). They have local contact centers functioning as front-line offices all over Sweden, but both agencies have drastically reduced the numbers of front-offices when they increase the provision of digital services.

Our case studies have taken place at the front-offices in the West Sweden Region, focusing on challenges in using the e-services and automatization of the users. How do the users approach the digital and automated systems and how are more users getting included? How do they meet and take on the common assignment to get the system work in the best way? How is trust towards the automated systems as well as the welfare state in general improved by the support of the human professionals? The issues were discussed with two strategically chosen managers at the front-line offices in each agency. The interviews focused on the outlined issues but also on very practical issues that were related to our observations studies at the agencies and similar previous studies on municipal contact centers [39].

\subsection{Discussions on digital divides at the agencies}

At the AF, handling the employment benefits the digital divides in form of access to technology was an obvious barrier. The agency met several problems with users lacking the technology. They have an ambition to support the users' access to digital technologies, but it is not always easy, as one of the managers told us:

All unemployed must leave a report every month, on what they did last month. It has been digitalized for a long time and the log-in was a four-digit password. But they changed it to make it more secure a few years. So, now you must access by e-ID. When we did this the numbers of digital users fell drastically. Today there are people asking for the paper form again. They do not know how to manage it digitally anymore. Some of the regulars we know in person, and we just give them the paper. But we try to encourage some of them to learn. Some bring up an old cell phone and say I cannot use the e-ID since I don't have a smart phone. Then we ask them if they have a computer and tell them that it is possible to use the computer. Then they say aha! We also ask if they have a bank card and when they say that they do, we ask them to go to their bank to get an e-ID at the card. We cannot fix it, we have to send them away.

This was also a barrier at the FK although they were a bit more positive regarding the users' trust in the 
digital services compared with the managers at the AF. They also have an ambition to support and coach the customers' access to digital technologies to all groups of users as stressed by a manager:

... our refugees are a huge group with us. And that is a challenge sometimes, many times, and with the language. Nobody is excluded and no one has said that: "no, we cannot help you". But we always aim to try, in our way, with good intentions, strengthen and pilot and guide, so that the customer actually becomes independent, because we must help others all the time.. So to get away from it, yes, to make it supportive is our journey, encouraging them to use their Bank-ID.

For those who do not have a bank ID and do not wish to acquire one, the agency is providing them with information on the alternative ways to use their services. But the agency does not inform or explain their clients about other authorities' public services and how the function.

As the digital development has increased during the recent years it is also a challenge for the managers to be updated and have actual competence as one of the respondents stresses:

So what you have to bring is the history, actually all (digital) services have not been around for a long time. The Swedish Tax Agency, the Social Insurance Agency have been working on this development in recent years and now, suddenly, in the past one and a half year something happens every day, so we are fully committed to keeping up with ourselves. We are constantly learning every day

This points at a common problem that we have met at the library as well, the street level bureaucrats interacting with the users try to promote and supporting digital services. But they cannot. They cannot provide the technology for e-ID. The public e-ID system in Sweden is managed by the private banks [40] and it is a common barrier for access to public digital services. In addition, low income households in unemployment support can get extra income support to cover costs for smart phones, wi-fi or tablets.

\subsection{Discussions on digital literacy at the agencies}

At the AF we also asked the manager which groups they saw as those most in need and he replied that it is the immigrants. However, the immigrants that come to AF, already have a working permit and have been through some basic Swedish training and they have usually also had some form of computer training and courses. So, this was an interesting explanation of one of the managers:

It is those that are newly arrived in Sweden, the immigrants. They need most help. But when we show them they get it. They can click through the forms quite easy, most of them. But they do not know how to go to the right page and what to do in the first place.

This shows that it is not really an issue of digital literacy but rather a need for public administration and management literacy they need support with. They have to know more about their new country and the governmental structures here, otherwise they cannot manage the digital services.

\subsection{Concluding remarks om digital diversity at the national agencies}

The public agencies lack guidelines and policies for addressing the diversity of the users' access to and competences about digital services and tools. Still it is obvious that they in practice do address these issues through daily work, but they lack the resources and the mission to support and empower the users, that instead turn to the libraries.

\section{Digital diversity - analysis, conclusions and some policy implications}

In this paper we have added to the current debates on digital divides and digital inclusion by an elaborative research overview and in relation to two case studies in Sweden. Our overall contributions point at the importance of inclusion and equality in these debates, and in particular the need to see the non-users and thirdly to discuss the potential of digital diversity. Our main empirical finding is also that digital literacy is embedded into governmental literacy when it regards digital government issues, that opens for a more elaborated integration of public administration theories.

\subsection{Lessons learned from the public libraries and national agencies}

It is obvious that the local public libraries and the service centers at the national governmental agencies still have indeed different interpretations of their assignments when it comes to digital inclusion. In both contexts they are aware of the importance of digital inclusion as stated in national policy documents. However, their awareness of the users' diverse digital 
literacy and uneven access to technology is frightening unequal.

The staff at the libraries, and in particular in Motala were they work more innovative in collaboration with the DigiDel-network provides additional access and strives to enhance digital literacy. The public agencies on the other hand lack such recourse and they just encourage digital inclusion with any tools nor specific resources, as summarized in the cross-presentation of the case studies.

Hereby we have shown the diversity of the needs among citizens as users of public services. This interaction points at the need of considering the interplay among digital divide, digital literacy and digital inclusion to address inequalities. However, we have learned through this study that there is indeed a diversity of digital inequalities.

Table 1: Cross-case summary

\begin{tabular}{|l|l|l|}
\hline & Public libraries & $\begin{array}{l}\text { Public } \\
\text { agencies }\end{array}$ \\
\hline $\begin{array}{l}\text { Digital } \\
\text { diversity }\end{array}$ & $\begin{array}{l}\text { Public computers } \\
\text { available }\end{array}$ & $\begin{array}{l}\text { No additional } \\
\text { resources }\end{array}$ \\
\hline $\begin{array}{l}\text { Digital } \\
\text { literacy }\end{array}$ & $\begin{array}{l}\text { Workshops and } \\
\text { drop-in coaching }\end{array}$ & $\begin{array}{l}\text { Just personal } \\
\text { encouragement }\end{array}$ \\
\hline $\begin{array}{l}\text { Digital } \\
\text { inclusion }\end{array}$ & $\begin{array}{l}\text { Library Act } \\
\text { Regional programs } \\
\text { Local work with } \\
\text { DigiDel }\end{array}$ & $\begin{array}{l}\text { Focus on } \\
\text { efficiency }\end{array}$ \\
No guidelines \\
\hline
\end{tabular}

\subsection{Diverse digital divides}

It is also worth noticing that there is a continuous development of digital technologies - there is always moving frontiers of digital access. As new digital technological devices are developed and public services are increasingly digitalized, the requirements for having access to public services are reconfigured, and those who need to access basic public services are required to have the technological equipment, and the know-how of how to acquire programs and applications, but also the knowledge of how public institutions and society in general works. Technological equipment such as smart phones are furthermore often expensive, and everyone cannot, and does not wish to, buy one. Also, the boundaries between the public and the private are becoming increasingly permeable, for instance as - in a Swedish context - the e-ID required to access many public services are provided by private banks. This might become a barrier for immigrants and paperless individuals, but also for others with insufficient digital literacy.

\subsection{Diverse forms of digital literacy}

The conceptualization of digital literacy becomes quite narrow here since we have focused the literature review by a limitation to digital government, a more extensive search on research relating to digital literacy would probably have extended and opened up the meanings and discussions on digital literacy, much more. But still the concept provides a contribution not at least when we can see how digital literacy relates to a form of public service literacy. There is a need for knowledge on digital tools and applications as well as on the structure and organization of the public administration and services. Our case studies also indicate that there is a need to enhance the literacy so to say regarding the citizens legal rights and duties. The citizen has to have competence on available services in order to "trigger" her search for digital public services.

Hence, our study indicates that - as digital technologies and services are becoming increasingly and seamlessly integrated into the social fabric - it becomes central to not only have access to technology and knowing how to use it (technological skill and know-how), but also to know of the social fabric in which technological services are embedded. Bijker [41] discuss the concept of socio-technical ensemble, which implies that the technological is comprised of a "combination of technical, social, organizational, economic and political elements". If (public) digital services are understood in terms of socio-technological ensembles [41] this would indicate that it is not enough to have access to and to possess knowledge about the technology, but that a requirement for being able to fully use digital services is to understand the sociotechnological ensemble of which they are part, that is, the complex webs of relations constituted by national legislation, of local institutions and relations, organizational practices, technological devices and applications, public and private actors and institutions, identification technologies and so forth.

It seems as though the concept of digital in the context of public services is relational - as it is constituted by an intersection, or a particular configuration of digital technologies, public services, design practices and digital knowledge and use practices on behalf of the users of those services - and that when some aspect or dimension of this configuration is reconfigured, the other aspects are required to change too. It also seems that those who find themselves in a disadvantaged position (in relation digitally inequality or diversity) are those who are otherwise in a vulnerable position of some sort - unemployed and in need for a new job, in need for pension, or some other form of compensation due to sickness (their own, their child, their spouse), or when they do not know how to fulfil their duties as citizens (such as completing a tax declaration). 
The indications that digital literacy is closely embedded into governmental literacy when it comes to digital government. Thus, there is a need to look into how governmental structures, organizations and polices are made transparent and clear in digital interfaces. This is not at least a challenge in states with high immigration and extensive public services as is the case for these empirical studies.

\subsection{Digital diversity - the variety of policies}

This paper has accentuated the need for continued conceptual and empirically grounded studies in the diversity of digital inequalities. There is a need to address this both through inductive case studies and theoretical conceptualization on social and economic development and inclusion. There is also a need to support a knowledge or even evidence-based policy formation in these areas, to avoid the risk of using the users as norms for development of services.

Both case studies above point at the need to elaborate on the complexity of digital inequalities, in particular in relation to digital government there is a need to enhance the understanding of the user and in particular the ones that are still non-users. We have seen in line with Robinson et.al., that arguee that there are relationships between digital inequalities and other forms of inequalities [2]. However, there is a need for research to look for inequalities in new terms as well and not take other forms for inequalities as given. Thus, we have to search for methods that open such perspectives beyond structures, norms and concepts. Robinson et al. further argued that disadvantages and inequalities merged through the ever more seamless integration of digital technologies into everyday practices, and thus there is a need to develop and apply methods and research approaches to build knowledge and contribute to a digital society for all.

\section{References}

[1] Rothstein, B. and J. Teorell, "What Is Quality of Government? A Theory of Impartial Government Institutions", Governance, 2008, 21(2), pp. 165-190.

[2] Robinson, L., S.R. Cotten, H. Ono, A. Quan-Haase, G. Mesch, W. Chen, J. Schulz, T.M. Hale, and M.J. Stern, "Digital inequalities and why they matter", Information, Communication \& Society, 2015, 18(5), pp. 569-582.

[3] Government Offices, For sustainable digital transfromation in Sweden - A Digital Stategy, 2017.

[4] Försäkringskassan, Försäkringskassans årsredovisning. 2013.
[5] Wihlborg, E., H. Larsson, and K. Hedstrom, "The Computer Says No!" - A Case Study on Automated Decision-Making in Public Authorities, 49th Hawaii International Conference on System Sciences (HICSS), USA, IEEE, 2016.

[6] Norris, P., "Digital divide: civic engagement, information poverty, and the Internet worldwide", Communication, society and politics, Cambridge University Press, Cambridge, 2001.

[7] Jaeger, P.T., J.C. Bertot, K.M. Thompson, S.M. Katz, and E.J. DeCoster, "The Intersection of Public Policy and Public Access: Digital Divides, Digital Literacy, Digital Inclusion, and Public Libraries", Public Library Quarterly, 2012, 31(1), pp. 1-20.

[8] Bertot, J.C., P.T. Jaeger, U. Gorham, N.G. Taylor, and R. Lincoln, "Delivering e-government services and transforming communities through innovative partnerships: Public libraries, government agencies, and community organizations", Information Polity: The International Journal of Government \& Democracy in the Information Age, 2013, 18(2), pp. 127138.

[9] Elg, M., P.-E. Ellström, M. Klofsten, and M. Tillmar, Sustainable development in organizations: studies on innovative practices, Elgar, Cheltenham, 2015.

[10] Heeks, R., Implementing and managing egovernment: an international text. SAGE, Thousand Oaks, 2006.

[11] Yildiz, M., "E-government research: Reviewing the literature, limitations, and ways forward", Government Information Quarterly, 2007, 24(3), pp. 646-665.

[12] Heeks, R. and S. Bailur, "Analyzing e-government research: Perspectives, philosophies, theories, methods, and practice", Government Information Quarterly, 2007, 24(2), pp. 243-265.

[13] Helbig, N., J.R. Gil-Garcia, and E. Ferro, "Understanding the complexity of electronic government: Implications from the digital divide literature", Government Information Quarterly, 2009, 26(1), pp. 89-97.

[14] Grönlund, Å. Connecting eGovernment to Real "Government - The Failure of the UN eParticipation Index. in Electronic Government", 10th IFIP WG 8.5 International Conference, (EGOV), The Netherlands, 2011.

[15] Axelsson, K., U. Melin, and I. Lindgren, "Exploring the importance of citizen participation and involvement in egovernment projects: Practice, incentives, and organization", Transforming Government: People, Process and Policy, 2010, 4(4), pp. 299 - 321.

[16] Garcia-Garcia, L.M. and J.R. Gil-Garcia, "Reconsidering the importance of context for the success of digital government: the case of legal vulnerability and extreme poverty in the provision of migration services at the Southern 
Mexican border", The 19th Annual International Conference on Digital Government Research: Governance in the Data Age, The Netherlands, 2018, pp. 1-7.

[17] van Deursen, A.J.A.M. and E.J. Helsper, "The ThirdLevel Digital Divide: Who Benefits Most from Being Online?", Communication and Information Technologies Annual, S.R. Cotten, et al., (eds.), Emerald Group Publishing Limited, pp. 29-52, 2015.

[18] van Deursen, A.J. and J.A. van Dijk, "The first-level digital divide shifts from inequalities in physical access to inequalities in material access", New Media \& Society, 2018. $\mathbf{0}(0)$, pp. 1-22.

[19] Park, S., "Digital inequalities in rural Australia: A double jeopardy of remoteness and social exclusion", Journal of Rural Studies, 2017, 54(Supplement C), pp. 399-407.

[20] Dodel, M. and F. Aguirre, "Digital inequalities' impact on progressive stages of e-government development", The 11th International Conference on Theory and Practice of Electronic Governance, ACM, Ireland, 2018, pp. 459-463.

[21] Davidsson, P. and A. Thoresson, Svenskarna och internet 2017, P. Matti (Ed), IIS, Stockholm, 2017

[22] Thompson, K.M., P.T. Jaeger, N.G. Taylor, M.M. Subramaniam, and J.C. Bertot, Digital literacy and digital inclusion: information policy and the public library, Rowman \& Littlefield, Lanham, 2014.

[23] Cordella, A. and N. Tempini, E-government and organizational change: Reappraising the role of ICT and bureaucracy in public service delivery, Government Information Quarterly, 2015, 32(3), pp. 279-286.

[24] Wihlborg, E. and J. Engstrom, "Bridging Digital Divides through Digital Media Buses: An Action Research Study on Digital Inclusion in Sweden. Conference for EDemocracy and Open Government (CeDEM), 2017.

[25] Wihlborg, E., En lösning som söker problem: hur och varför lokala IT-policyer utvecklas i landsbygdskommuner. Linköping studies in arts and science, Linköping, Vol. 225. 2000 .

[26] Bengs, A., S. Hägglund, A. Wiklund-Engblom, J. Majors, and A. Ashfaq, "Designing for social inclusion of immigrant women: the case of TeaTime Innovation", The European Journal of Social Science Research, 2018, 31(2), pp. 106-124.

[27] Bertot, J. C., Charles R. McClure, and Paul T. Jaeger, "The Impacts of Free Public Internet Access on Public Library Patrons and Communities", The Library Quarterly, 2008, 78(3), pp. 285-301.

[28] Wihlborg, E., "Legitimate e-Government - Public eServices as a Facilitator of Political Legitimacy", in Hawaii
International Conference on System Sciences (HICSS), USA, IEEE, 2014.

[29] Gidlund, K.L. and J. Sefyrin, "Problematizing the Participatory Subject in Demands Driven Development of Public Sector", Electronic Government and Electronic Participation: Joint Proceedings of Ongoing Research and Projects of IFIP WG 8.5 EGOV and ePart, Irerland, 2014.

[30] Moore, H.L., A passion for difference: essays in anthropology and gender, Polity, Cambridge, 1994.

[31] Eisenhardt, K.M., "Building Theories from Case Study Research", The Academy of Management Review, 1989, 14(4), p. 532-550.

[32] Alvesson, M. and D. Kärreman, Qualitative research and theory development: mystery as method, SAGE, Thousand Oaks, 2011.

[33] Gustafsson, M., J. Larsson, and E. Wihlborg, "It is unbelievable how many come to us: A study on librarians' perspectives on digital inclusion in Sweden", The 15th Scandinavian Workshop on e-Government, Denmark, 2018.

[34] Andersson, J., "The People's Library and the Electronic Workshop: Comparing Swedish and British Social Democracy", Politics \& Society, 2006, 34(3), pp. 431-460.

[35] Bertot, J.C., P.T. Jaeger, and C.R. McClure, "Citizencentered e-government services: benefits, costs, and research needs", International conference on Digital government research, Digital Government Society of North America, Canada, 2008, pp. 137-142.

[36] SFS, Bibliotekslag, 2013:801, Sveriges Riksdag.

[37] Swedish Library Association, Promoting the development of a democratic society: The Swedish Library Act according to the legislator, Stockholm, 2015.

[38] Region Östergötland, Regional biblioteksplan för Östergötland, 2016.

[39] Bernhard, I. and E. Wihlborg, Regional e-governance: Promoting Entrepreneurial Behavior in Public Administration, in Agglomeration, Clusters and Entrepreneurship. Studies in Regional Economic Development, Elgar, Cheltenham, 2014.

[40] Söderström, F., Introducing public sector eIDs: The power of actors' translations and institutional barriers. Linköping Studies in Arts and Science, Linköping University Electronic Press, Linköping, 2016.

[41] Bijker, W.E., How is technology made? That is the question!, Cambridge Journal of Economics, 2009, 34(1), pp. 63-76. 